Int. J. Speleol. 16 (1987), pp. 17-31

\title{
The role of gradualism and punctuation in cave adaptation
}

\author{
David C. Culver*
}

\begin{abstract}
SUMMARY
The theory of punctuated equilibrium, offers a potential explanation for the profound morphological changes that accompany isolation in caves. I consider three aspects of punctuation theory: the association of morphological change with speciation; periods of stasis; and the number of genes controlling a trait. If the evolution of cave organisms is associated with speciation, then speciose groups and cave species derived from other cavelimited species should show increased adaptation. Analysis of Kane and Barr's data on the subspecies of Neaphaenops tellkampfi and Holsinger's data on crangonyctid amphipods fails to provide any support for the hypothesis. If the evolution is characterized by long periods of stasis, then directional selection should be rare. An estimate of selection in a cave population of Gammarus minus indicates that directional selection is occurring. Third, if punctuation is important, characters associated with isolation in caves should be controlled by a single gene. Wilkens and others have found most characters in cave Astyanax to be controlled by between 3 and 7 genes. It is more useful to frame the question of evolutionary change accompanying cave invasion in terms of adaptive topographies. Several examples of its use are discussed, including assessing the role in selection in structural reduction, and the role of isolation in adaptation to cave life.
\end{abstract}

\section{INTRODUCTION}

In the past decade a forceful group of critics of neo-Darwinism have emerged. The initial impetus for the critique was the contention bv some paleobiologists that the fossil record did not correspond to a model of gradual change in morphology, but rather consisted of long periods of no change (stasis) followed by short bursts of morphological change, termed punctuation by Eldredge and Gould (1972). An alternative mechanism to the gradual action of natural selection has been proposed: namely the idea that morphological change is primarily asso-

* Department of Biology, The American University, Washington, D.C. 20016 U.S.A. 
ciated with speciation, often brought about by mutations of rather large effect. This theory, or more accurately this set of theories, has been the subject of considerable controversy (e.g. Charlesworth, Slatkin and Lande, 1982; Gould and Eldredge, 1986). It is not my purpose here to review the controversy, nor to determine how much of punctuated equilibrium theory is new and non-neo-Darwinian, rather it is my purpose to review several key ideas that have emerged in this controversy and ascertain their relevance to adaptation to the cave environment.

At the same time as the large controversy concerning punctuated equilibrium has been swirling about in evolutionary biology, there has been a smaller controversy in biospeleology, one that raises many of the same questions. The standard view of adaptation to cave life has been that adaptation requires (1) that cave populations are genetically isolated from surface ancestors, and (2) that structural reduction (eye and pigment loss) are at least indirectly selected for because the energy savings from such reduction can be used in the elaboration and size increase in extra-optic sensory structures such as antennae in arthropods and lateral line systems in fish. Both of the tenets have been challenged. Howarth (1980), with his adaptive shift theory, has questioned the role of isolation in adaptation; and Culver (1982) and Wilkens (1985) with the theory of neutral mutations, have questioned the role selection plays in structural reduction.

This paper has two main parts. First, three pivotal questions raised by the theory of punctuated equilibrium will be considered in light of available data on cave organisms. These questions are:

(1) Is morphological change in cave organisms associated with speciation?

(2) Are there periods of stasis in cave animals?

(3) Are adaptive traits controlled by a few genes of large effect?

The second main part of the paper will be a consideration of the potential that the concept of adaptive surfaces offers in clarifying questions concerning cave adaptation.

\section{THE CONNECTION BETWEEN SPECIATION AND MORPHOLOGICAL CHANGE}

Perhaps the single most important characteristic shared by the various critiques of neo-Darwinism is that morphological change is almost invariably associated with speciation. If this hypothesis is true, then one prediction is that highly speciated groups should be more adapted to the cave envi- 
ronment than species-poor groups. Table 1 summarizes two such comparisons for some cave amphipod species. One measure of adaptation to the cave environment is the increase in size of antennae relative to the body (Culver, 1982). More highly cave adapted species should have relatively longer antennae. In the Ozark Plateau of central United States, two genera of amphipods are commonly found in caves - the species-poor Allocrangonyx with less than a dozen species world-wide and only 2 in the Ozark (Holsinger, 1971) and the species-rich Stygobromus with more than 100 species world-wide and nearly a dozen species in the Ozark Plateau (Holsinger, 1967; 1987). Yet there is no significant difference in antennal-body ratios between the two genera in the Ozark (Table 1). An additional comparison using Stygobromus in different regions also has bearing on the question. All but two species of Stygobromus are known from North America, the other two known from deep lakes in Siberia (Holsinger, 1987). A comparison of species from deep lakes in the western United States with $\mathrm{Si}$ berian species from the same habitat fails to indicate any dif-

Table 1 - Maximum antenna 1/body length ratios for selected subterranean amphipod species. Data from Holsinger (1967; 1971; 1974; 1987)

SPECIES

RATIO

Ozark Plateau:

Allocrangonyx hubrichti

A. pellucidus

Stygobromus barri

S. bowmani

$S$. clantoni

S. elatus

S. heteropodus

S. montanus

S. ozarkensis

Deep Lakes:

Stygobromus pusillus (Teletskoye)

S. lacicolus (Tahoe)

$S$. tahoensis (Tahoe)
.70

.65

$$
\bar{x}=
$$

$.67 \pm .02$

.85

.65

.65

.65

.70

.75

.90

$$
\bar{x}=\quad .74 \pm .04
$$


ference in adaptation. Therefore, Stygobromus fails to provide any support for the idea that speciation plays an important role in morphological change in subterranean populations.

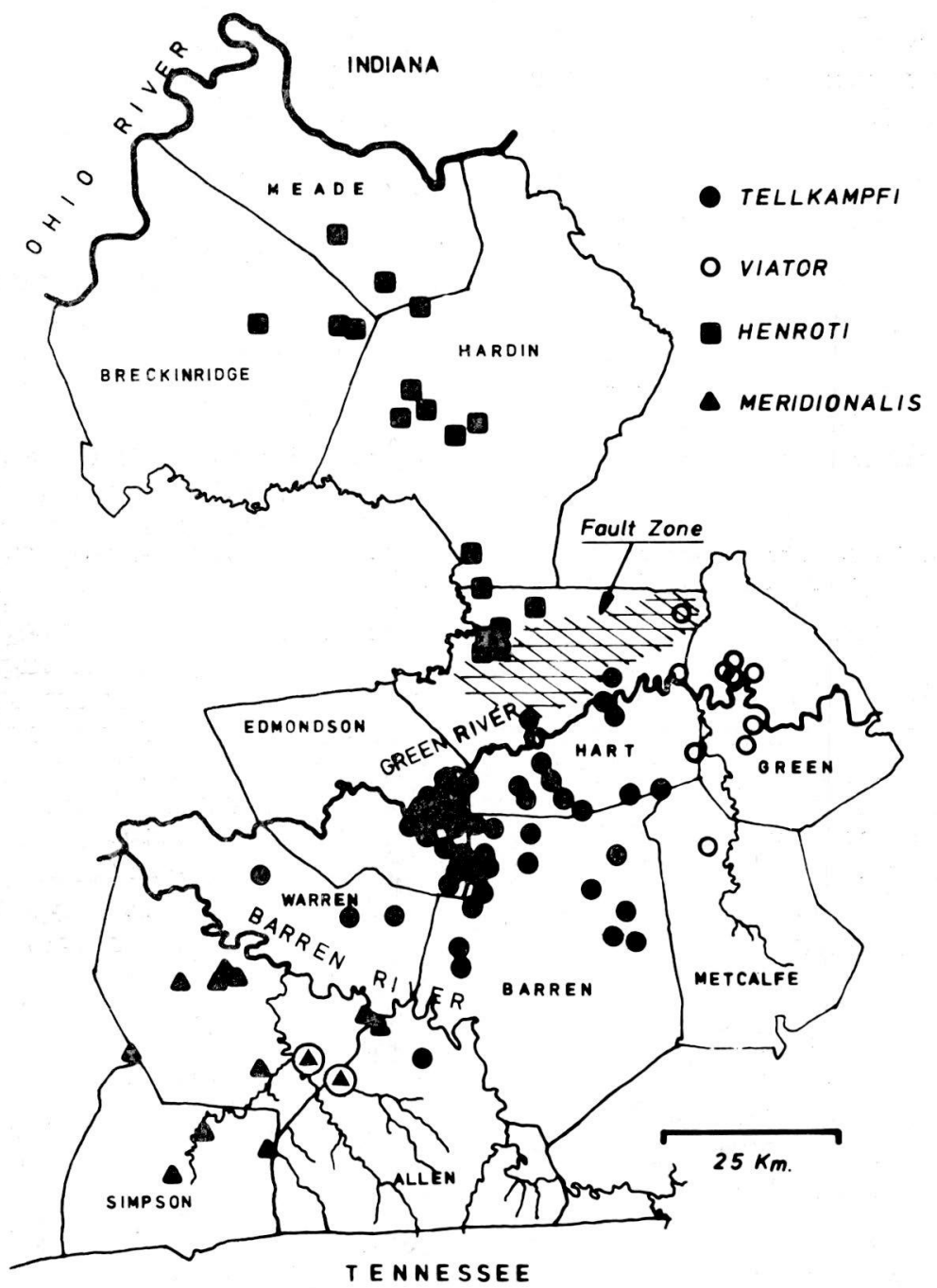

Fig. 1 - Distribution of the four subspecies of the carabid beetle Neaphaenops tellkampfi in west central Kentucky. The triangles within a circle are hybrids between meridionalis and tellkampfi subspecies. Modified from Barr (1979). 
Table 2 - Rogers' coefficients of genetic similarity (S) for the four subspecies of Neaphaenops tellkampfi. From Kane and Brunner (1986).

\begin{tabular}{lcccc}
\hline & tellkampfi & meridionalis & viator & henroti \\
\hline tellkampfi & .963 & & & \\
meridionalis & .730 & .956 & & \\
viator & .737 & .740 & 963 & \\
henroti & .963 & .748 & .741 & .975 \\
\hline
\end{tabular}

Arguably the most thoroughly studied North American cave species from an ecological (Kane and Ryan, 1983), genetic (Kane and Brunner, 1986), and morphological (Barr, 1979) point of view is the carabid beetle Neaphaenops tellkampfi. According to Barr, N. tellkampfi originally invaded caves in the southern part of its range (Fig. 1), within the range of the subspecies meridionalis. Via subterranean dispersal it spread to the area occupied by the subspecies tellkampfi, and then to the areas occupied by the subspecies henroti and viator. Genetic distances between the subspecies, based on electromorphs of 9 loci, are as great as that between many species, except for tellkam.pfi and henroti (Table 2). If morphological change accompanies speciation, then tellkampfi should be more highly adapted than meridionalis, and henroti and viator should be more highly adapted than tellkampfi. But the four subspecies differ only in very subtle morphological ways (Barr, 1979), and none of these differences appear to be associated with adaptation to the cave environment. As with Stygobromus, Neaphaenops tellkampfi provides no support for the hypothesis that morphological change is associated with speciation.

\section{THE EVIDENCE FOR STASIS}

If for most of the phyletic history of a species there is no morphological change, such periods of stasis should be characterized by the absence of directional selection, no genetic variation for selection to act upon, or by strong stabilizing selection. Pearson (1903) first showed that multivariate statistics could be used to discern the effect of direct and indirect selection on characters. Recently Lande and Arnold (1983) have extended this work to show how multiple regression methods can be used to measure the effects of directional and stabilizing selection. 
Ross Jones of Northwestern University has utilized Lande and Arnold's methodology in measuring some components of selection in a cave population of the amphipod Gammarus minus. Jones took advantage of the fact that male G. minus carry females (amplexus) for several weeks prior to fertilization. In a collection of nearly 300 individuals from Organ Cave, individuals in amplexus were assigned a fitness of 1 and individuals not in amplexus were assigned a fitness of 0 . Thus he measured sexual selection and part of fecundity selection, but he did not measure differences in mortality. He measured head capsule length, eye facet number, and first antennal flagellar segment number. Eye facet number and antennal flagellar segment number were regressed on head length, and the residuals obtained were used for the multivariate analysis of selection parameters. This eliminates overall size effects from the two variables. Four parameters of directional selection were obtained:

(1) $\mathrm{S}$, the selection differential, is the change in the mean of a character during an episode of selection, and estimates the effect of direct and indirect selection on a trait;

(2) $i$, the selection intensity, is the standardized $S$ $(i=S / S . D$.$) , where S.D. is the standard deviation of the char-$ acter;

(3) $\beta$, the selection gradient, is the partial regression coefficient of relative fitness on a character, and measures only the direct effects of selection on a trait; and

(4) $\beta^{\prime}$, the standardized selection gradient, is standardized $\beta$, calculated directly from the multiple regression model using standardized character measures $\left(\mathrm{X}^{\prime}=(\mathrm{x}\right.$-avg.X)/S.D.X).

Two parameters of stabilizing selection, here defined as selection causing changes in the variance of a trait, were obtained:

(1) $\lambda$, the stabilizing selection gradient, is the analog of $\beta$ above and;

(2) $\lambda$, the standardized stabilizing selection gradient, is the analog of $\beta$ ' above.

More details on this technique can be found in Lande and Arnold (1983) and Endler (1986).

The results of the analysis are summarized in Table 3 . For males, there was significant directional selection on head length and eye facet number, but not on antennal segment number. There was significant stabilizing selection on head length and antennae, but not on eyes. For females the pattern was the same except the stabilizing selection occurred on eyes and antennae, but not on head length. How are these data to be interpreted? First, selection on head length is probably meaningless because different aged individuals were 


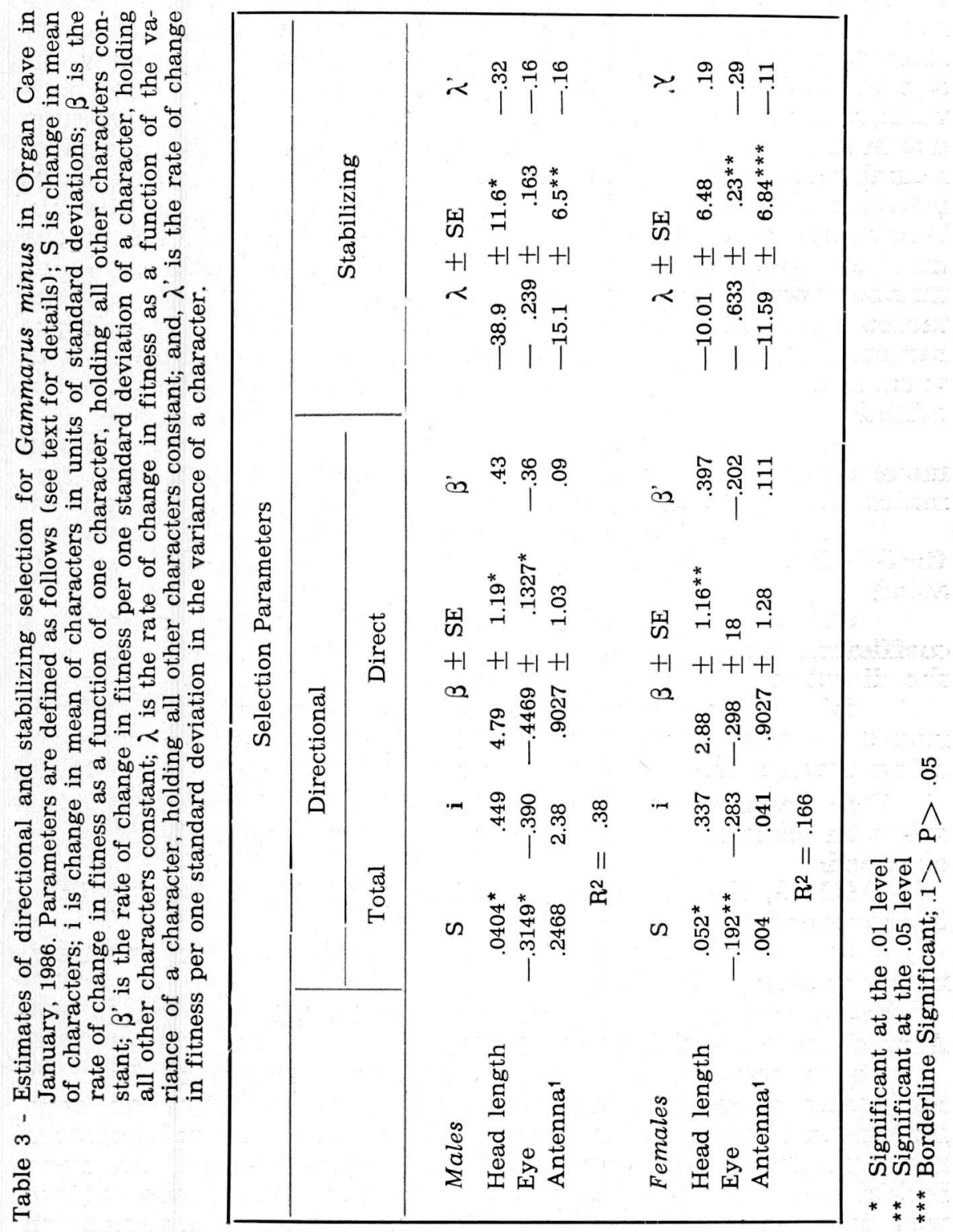


present, and these values simply reflect that older individuals are larger. While head length at any specific age is heritable (Fong, 1985), heritability of head length of a sample of mixed ages, as is the case here, is low. Second, there is significant directional selection against large eyed individuals in both sexes. While the absence of detectable directional selection on antennae is surprising, there is clearly directional selection occuring. Since eye facet number is highly heritable (Fong, 1985) and selection is occurring, the mean phenotype is changing. That is, the population is not in a period of stasis. Third, stabilizing selection is also present, but may largely be an artifact of the fact that many forms of directional selection, such as truncation selection, reduce the variance as well as change the mean. That is, except for male antennae, there is no clear evidence for stabilizing selection in the sense that both extremes of the distribution are selected against.

In sum, the data of Jones, even though preliminary, provide convincing evidence for directional selection. The multivariate techniques used hold exceptional promise not only for the study of adaptation to cave life, but for the study of adaptation in general.

\section{ARE ADAPTIVE TRAITS POLYGENIC?}

If morphological change happens rather suddenly and in conjunction with speciation, then these changes should be the result of changes at only one or perhaps two loci, since the simultaneous occurrence of many mutations all with small effects in highly improbable. Wilkens (1985) has analyzed the gonetic basis of a series of traits in the cave fish Astyanax fasciatus. All are polygenic except for melanin content of the melanophore (Table 4), and the melanophore system as a whole is polygenic. There is, however, some evidence that eye

Table 4 - Minimum number of loci involved in various traits of cave populations of Astyanax fasciatus (from Wilkens, 1985)

Character

Eye Size

Melanophore Number

Melanin Content of Melanophore

Food Swimming Angle

Taste Buds
Number of Loci 

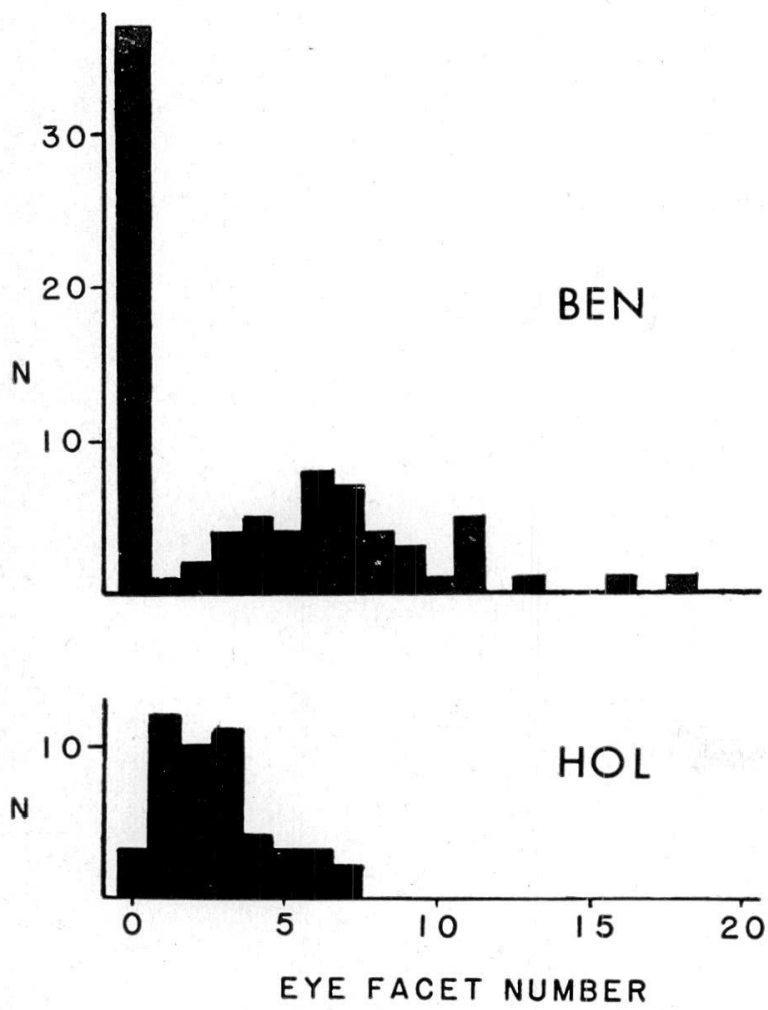

Fig. 2 - Frequency of distribution of ommatidia (lens numbers) of two populations of the amphipod Gammarus minus from Benedict's Cave (BEN) and The Hole (HOL) in Greenbrier Co.. West Virginia. For details see Culver (1987).

facet number in some populations of Gammarus minus is controlled by a single gene while in others it is polygenic (Culver, in press). The evidence is this. In some populations the distribution of eye facet numbers is unimodal and approximately normal, suggesting polygenic control. An example is The Hole in Fig. 2. In other populations the distribution of eye facet number is bimodal, suggesting control by a single gene difference. An example is Benedict's Cave in Fig. 2. The data in Fig. 2 are based only on phenotypes not genotypes, although heritability of eye facet number is likely to be high (Fong, 1985). In sum, neither Astyanax nor Gammarus provide overwhelming support for single gene control of a trait. 


\section{AN ALTERNATIVE}

There is little evidence to support a punctuationist view of cave adaptation. But this still leaves us with controversies concerning the causes of regressive evolution and the role of isolation in cave adaptation. There are at least two problems with the punctuationist view of cave adaptation. First, punctuation and stasis were originally used to explain sequences in the fossil record, sequences that generally involved the evolution of higher categories (genera, families, etc.). Cave adaptation rarely involves the origin of higher categories so that punctuational equilibria may be inappropriate for reasons of scale. Second, for the most part, punctuational equilibrium theory has not been formulated with any clear genetic basis.

A theory that is both at the appropriate scale and is at least implicitly genetic is the idea of an adaptive topography. Originally formulated by Wright (1932) in terms of gene frequencies, his basic idea was to let the $\mathrm{x}$-axis and y-axis graph gene frequencies at two loci, and let the z-axis represent fitness. This creates an adaptive surface in which selection causes populations to move uphill to adaptive peaks. Provine (1986) has pointed out some ambiguities in the original formulation, but many of these problems disappear if the x-axis and y-axis are some measure of phenotype (see Simpson, 1944). A representative phenotypic adaptive topography is shown in Figure 3 . Implicit in the phenotypic adaptive topography is that the characters are polygenically controlled, which allows for small changes in phenotype. Except for genetic constraints such as pleiotropy and linkage, populations will, as a result of selection, come to occupy peaks.

The neutralist-selectionist controversy is depicted in Figure 4 , with the two phenotypic measurements being antennal size and eye size. If reduced characters, such as eyes, are selectively neutral, then the adaptive topography will be that depicted in the top frame, with the population coming to occupy a ridge as a result of selection for increased antennae. Only the accumulation of structurally reducing, selectively neutral mutations (see Culver, 1982) will cause the population to have reduced eyes. One prediction of this model is that species will likely evolve increased antennal size before reduced eye size. The selectionist model is depicted in the bottom half of Figure 4. In this case selection operates both to reduced eye size and increase antennal size. In this case, there is no reason to expect species to increase antennal size before decreasing eye size.

The role of isolation is depicted in Figure 5 . In the top frames, the original adaptive peak of the epigean population 
Phenotypic Adaptive Topographics
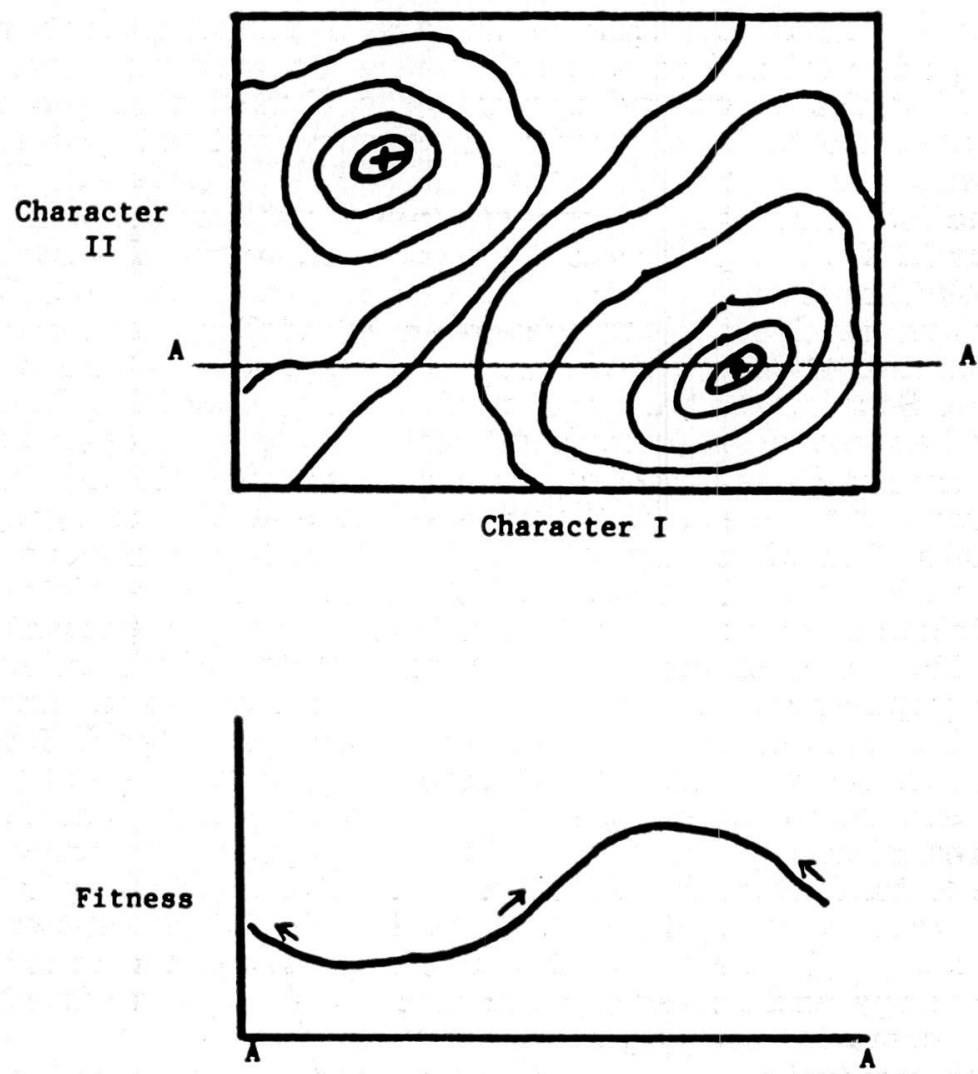

Fig. 3 - A sample phenotypic adaptive topography. Two morphological measurements (e.g., eye size and antenna size) are plotted on the $\mathrm{x}$ - and $\mathrm{y}$-axis. The $\mathrm{z}$-axis represents fitness. The lower frame is a slice through the adaptive topography. The arrows indicate direction that a population will move as a result of selection.

(large eyes and small antennae) disappears when the population is isolated in caves. The population then evolves in a straightforward manner to a small eyed, large antennae population, which is the cave adaptive peak. However, if isolation is not necessary, and the population invades the cave habitat but still retains contact with the surface population, then the epigean adaptive peak remains in addition to the new cave adaptive peak. This is depicted in the bottom frames of Figure 5. The problem now is that for cave adaptation to proceed, the population must cross the valley, an adaptive low. 


\section{Neutralist}

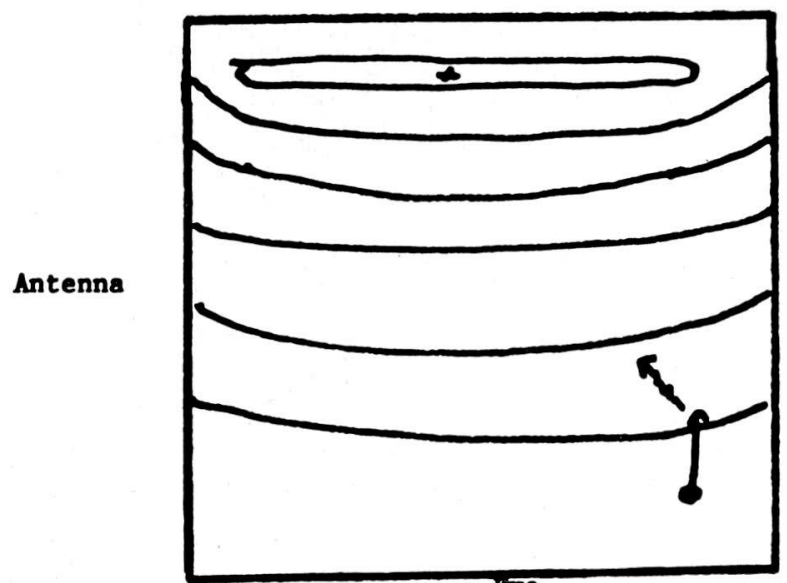

kȳe

\section{Selectionist}

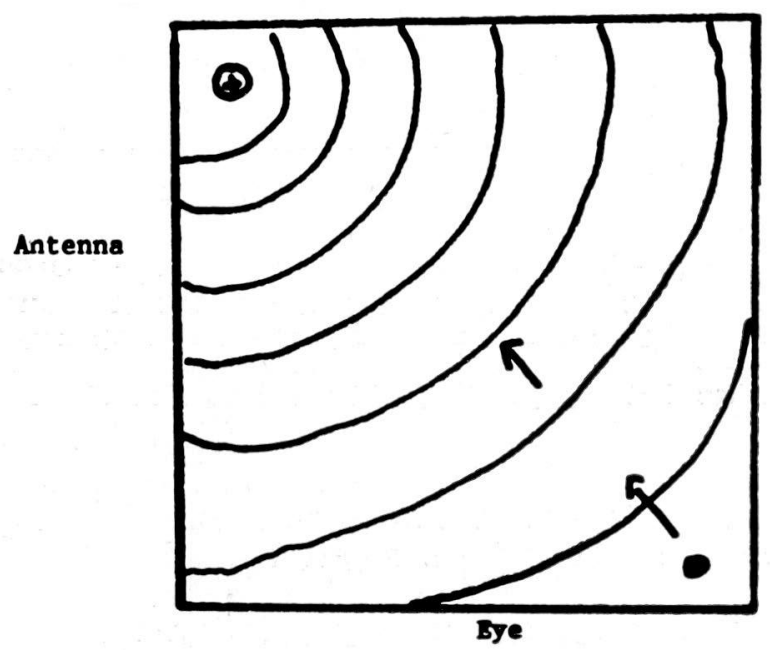

Fig. 4-Hypothetical adaptive topographies for eye reduction in which no direct or indirect selection is involved (top panel) and in the case when selection for eye reduction is involved (bottom panel). 

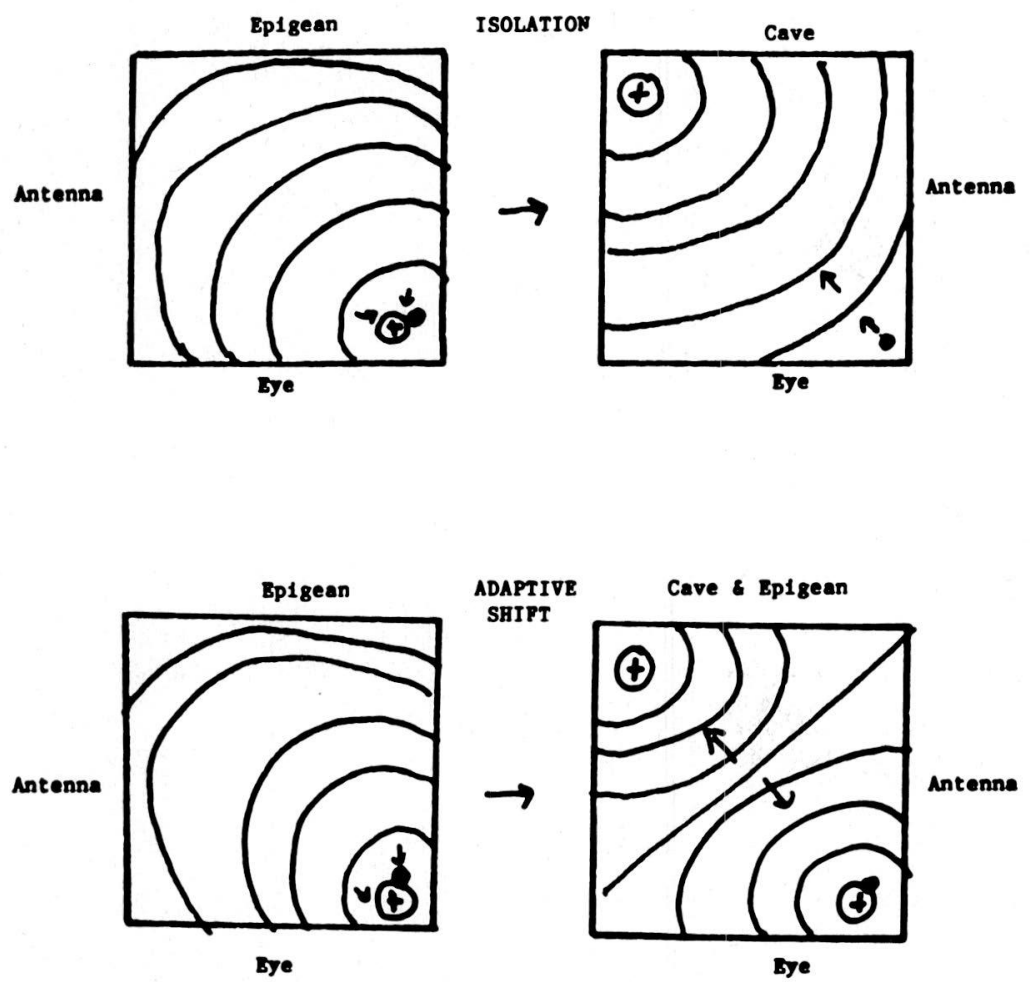

Fig. 5 - Hypothetical adaptive topographies in the case of isolation in caves (above) and in the case of adaptive shift without isolation (below).

Selection, by itself, will not result in a valley crossing, since selection acts to move a population toward a local peak (see Fig. 3). The problem of reaching a new adaptive peak is a problem that has occupied evolutionary theorists for decades, and brings us full cycle back to the question of punctuated equilibria. Wright's (1932) shifting balance theory suggested that the optimal conditions for reaching a new adaptive peak occurred in a subdivided population with extensive pleiotropy, with genetic drift playing an important role. Goldschmidt (1940), considered by some to be the intellectual father of punctuated equilibrium theory, argued that macromutations were the major source of new adaptive peaks. In this case, such a rare mutation is most likely in a very large population. Finally, Lande (1985) demostrated that in the case of phenotypic adaptive topographies, genetic drift in small population was the most likely means of a population evolving to a new adaptive peak. 
These examples by no means exhaust the potential for adaptive topographies, but are intended to show that they are likely to be useful. If they are indeed useful, then a major effort needs to be made to measure fitness (see above), and to begin to construct some adaptive topographies.

\section{ACKNOWLEDGEMENTS}

I am most grateful to Professor Valerio Sbordoni for inviting me to 51st meeting of the Unione Zoologica Italiana, and for organizing the symposium on "Speciation and adaptation to cave life: gradual vs. rectangular evolution". Mr. Ross Jones of Northwestern University provided the analysis of selection, a critical part of the paper. The paper benefitted from comments by D. Fong, R. Jones, and T. Kane. Research was supported by a grant from the National Science Foundation (BSR 8415862).

\section{REFERENCES}

BARR, T.C. 1979. The taxonomy, distribution, and affinities of Neaphaenops, with notes on associated species of Pseudanophthalmus (Coleoptera, Carabidae). Amer. Mus. Novitates No. 2682.

CHARLESWORTH, B., M. SLATKIN, and R. LANDE. 1982. A neo-Darwinian commentary on macro-evolution. Evolution 36: 474-498.

CULVER, D.C. 1982. Cave life. Harvard Univ. Press, Cambridge, Mass.

CULVER, D.C. 1987. Eye morphometrics of cave and spring populations of Gammarus minus (Amphipoda: Gammaridae). J. Crustacean Biol. 7: $136-147$.

ELDREDGE, N., and S.J. GOULD. 1972. Punctuated equilibria: an alternative to phyletic gradualism, p. 82-115. In T.J.M. Schopf (ed.), Models in paleobiology. Freeman, Cooper, and Co., San Francisco.

ENDLER, J.A. 1986. Natural selection in the wild. Princeton Univ. Press, Princeton, N.J.

FONG, D.W. 1985. A quantitative genetic analysis of regressive evolution in the amphipod Gammarus minus Say. Ph. D. Diss., Northwestern Univ., Evanston.

GOLDSCHMIDT, R. 1940. The material basis of evolution. Yale Univ. Press. New Haven.

GOULD, S.J., and N. ELDREDGE. 1986. Punctuated equilibrium at the third stage. Syst. Zool. 35: 143-148.

HOLSINGER, J.R. 1967. Systematics, speciation, and distribution of the subterranean amphipod genus Stygonectes (Gammaridae). U.S. Nat. Mus. Bull. No. 259.

HOLSINGER, J.R. 1971. A new species of the subterranean amphipod genus Allocrangonyx (Gammaridae), with a redescription of the genus and remarks on its zoogeography. Int. J. Speleol. 3: 317-331. 
HOLSINGER, J.R. 1974. Systematics of the subterranean amphipod genus Stygobromus (Gammaridae), part I; species of the western United States, Smithsonian Contrib. Zool. No. 160.

HOLSINGER, J.R. 1987. Redescription of the stygobiont amphipod crustacean Stygobromus pusillus (Crangonyctidae) from the Soviet Union, with comments on taxonomic and zoogeographic relationships. J. Crustacean Biol. 7: 249-257.

HOWARTH, F.G. 1980. The zoogeography of specialized cave anilmals: a bioclimatic model. Evolution 34: 394-406.

KANE, T.C., and G.D. BRUNNER. 1986. Geographic variation in the cave beetle Neaphaenops tellkampfi (Coleoptera: Carabidae). Psyche 93.

KANE, T.C., and T. RYAN. 1983. Population ecology of carabid cave beetles. Oecologia 60: 46-55.

LANDE, R. 1985. Expected time for random genetic drift of a population between stable phenotypic states. Proc. Nat.. Acad. Sci. (U.S.A.) 82: 7641-7645.

LANDE, R., and S.J. ARNOLD. 1983. The measurement of selection on correlated characters. Evolution 37: 1210-1226.

PEARSON, K. 1903. Mathematical contributions to the theory of evolution. XI. On the influence of natural selection on the variability and correlation of organs. Phil. Trans. Royal Soc. London A 200: 1-66.

PROVINE, W.B. 1986. Sewall Wright and evolutionary biology. Univ. Chicago Press, Chicago.

SIMPSON, G.G. 1944. Tempo and model in evolution. Columbia Univ. Press, New York.

WILKENS, H. 1985. The evolution of polygenic systems, studies on epigean and cave populations of Astyanax fasciatus (Characidae, Pisces). Nat. Speleol. Soc., Bull. 47: 101-108.

WRIGHT, S. 1932. The roles of mutation, inbreeding, crossbreeding, and selection in evolution. Proc. Sixth Int. Congr. Genetics 1: 356-366. 